\title{
Cervical Pathology Following HPV Vaccination in Greece: A 10-year HeCPA Observational Cohort Study
}

\author{
EVANGELOS PARASKEVAIDIS ${ }^{1}$, ANTONIOS ATHANASIOU ${ }^{2}$, MARIA PARASKEVAIDI $^{2}$, EVRIPIDIS BILIRAKIS $^{3}$, \\ GEORGIOS GALAZIOS ${ }^{4}$, EMMANUEL KONTOMANOLIS ${ }^{4}$, KONSTANTINOS DINAS ${ }^{5}$, \\ ARISTOTELIS LOUFOPOULOS ${ }^{5}$, MARIA NASIOUTZIKI ${ }^{5}$, IOANNIS KALOGIANNIDIS ${ }^{6}$, \\ APOSTOLOS ATHANASIADIS ${ }^{6}$, ALEXIOS PAPANIKOLAOU ${ }^{5}$, ANASTASIA VATOPOULOU ${ }^{7}$, \\ GREGORIOS GRIMBIZIS ${ }^{7}$, DIMITRIOS TSOLAKIDIS ${ }^{7}$, ALEXANDROS DAPONTE ${ }^{8}$, GEORGE VALASOULIS ${ }^{8}$, \\ STELLA GRITZELI ${ }^{9}$, GEORGIOS MICHAIL ${ }^{10}$, GEORGIOS ADONAKIS ${ }^{10}$, MINAS PASCHOPOULOS ${ }^{1}$, \\ ORESTIS TSONIS ${ }^{1}$, MARIA-EUGENIA ANAFORIDOU ${ }^{1}$, ANNA BATISTATOU ${ }^{11}$, MARIA KYRGIOU $^{2}$ \\ and the HeCPA (Hellenic Cervical Pathology Academic) Group \\ ${ }^{1}$ Department of Obstetrics and Gynaecology, University Hospital of Ioannina, Ioannina, Greece; \\ ${ }^{2}$ Institute of Reproductive and Developmental Biology, Department of Metabolism, \\ Digestion and Reproduction, Imperial College London, London, U.K.; \\ ${ }^{3}$ Department of Obstetrics and Gynaecology, IASO Hospital, Athens, Greece; \\ ${ }^{4}$ Department of Obstetrics and Gynaecology, University Hospital of Alexandroupolis, Alexandroupolis, Greece; \\ ${ }^{5}$ Second Department of Obstetrics and Gynaecology, University of Thessaloniki, Thessaloniki, Greece; \\ ${ }^{6}$ Third Department of Obstetrics and Gynaecology, University of Thessaloniki, Thessaloniki, Greece; \\ ${ }^{7}$ First Department of Obstetrics and Gynaecology, University of Thessaloniki, Thessaloniki, Greece; \\ ${ }^{8}$ Department of Obstetrics and Gynaecology, University Hospital of Larissa, Larissa, Greece; \\ ${ }^{9}$ Department of Obstetrics and Gynaecology, General Hospital of Larissa, Larissa, Greece; \\ ${ }^{10}$ Department of Obstetrics and Gynaecology, University Hospital of Patras, Patras, Greece; \\ ${ }^{11}$ Department of Pathology, University Hospital of Ioannina, Ioannina, Greece
}

\begin{abstract}
Background: In Greece the population-level impact of HPV vaccination is unknown due to lack of official registries. This study presents in a pragmatic frame the comparison of cervical pathology data between $H P V$ vaccinated and unvaccinated women referred for colposcopy. Patients and Methods: This is an observational prospective cohort study performed in 7 academic Obstetrics and Gynaecology Departments across Greece between 20092019. Cases were women that had completed HPV vaccination before coitarche and were referred for colposcopy due to abnormal cytology. For each vaccinated woman an unvaccinated matched control was selected. Results: A total of 849 women who had been vaccinated
\end{abstract}

This article is freely accessible online.

Correspondence to: Professor Evangelos Paraskevaidis, Department of Obstetrics and Gynaecology, University Hospital of Ioannina, University Campus, Leof. Stavrou Niarchou, Ioannina, 451 10, Greece. Tel: +30 6944981000, email: vangelispar@hotmail.com

Key Words: HPV, vaccine, vaccination. before coitarche and 849 unvaccinated controls were recruited. The combination of cytological, colposcopic and molecular findings necessitated treatment in only a single case among vaccinated (0.1\%) and in $8.4 \%$ among unvaccinated. Conclusion: HPV vaccination at a proper age can markedly reduce development of severe cervical precancers and consequently the need for treatment, as well as their long-term related obstetrical morbidity.

Cervical cancer had been one of the most common malignancies in females prior to introduction of Pap test and initiation of screening. Screening programmes (secondary prevention) have led to reduced cervical cancer incidence and mortality rates $(1,2)$, thanks to the early discovery of preinvasive cervical lesions and their treatment before progression to cancer. Human papillomavirus (HPV) vaccination (primary prevention) promises to further reduce, or even eliminate, cervical cancer burden (3). The efficacy of HPV vaccines has been documented in randomised clinical trials and is up to $99 \%$ for prevention of cervical intraepithelial neoplasia (CIN2+) related to vaccine-specific HPV types in HPV-naïve women (4). Observational data have also shown a reduction of CIN2+ lesions in the general population (5). 
Coverage of cervical cancer screening varies around the globe and is approximately $20 \%$ for developing and $60 \%$ for developed countries (6). The same pattern is also observed for HPV vaccination, with higher uptake rates in highincome countries (more developed vs. less developed countries: $5.4 \%$ vs. $0.5 \%$ for all ages; $33.6 \%$ vs. $2.7 \%$ for ages 10-20 years) (7). In Greece there are no official registry-based records for coverage with regards to screening (which is opportunistic) or HPV vaccination (which, albeit being state-funded until 18 years of age, is not based on a national school-based programme but rather on parents' initiative). Nonetheless, most authorities accept that coverage for both screening and HPV vaccination lies around 30-40\%.

The aim of this study was to present cervical pathology data (i.e. cytological and colposcopic results) for vaccinated women who were referred to academic colposcopy clinics across Greece due to abnormal cytology of any grade, and compare them to the findings of matched unvaccinated controls.

\section{Patients and Methods}

This observational prospective cohort study took place in the colposcopy clinics of the majority of academic Departments of Obstetrics and Gynaecology in Greece (Ioannina, Alexandroupolis, 3 Departments in Thessaloniki, Larissa and Patras), during 20092019. The coordinating centre was the academic Department of Obstetrics and Gynaecology in Ioannina.

For women that had completed HPV vaccination before sexual debut and were referred to the colposcopy clinics due to abnormal cytology of any grade, demographic data (age, education level), lifestyle risk (age at onset of sexual intercourse, number of sexual partners, smoking, frequency of condom use), as well as the results of the referral cytology, were recorded. All colposcopic evaluations were performed by the lead colposcopist in each Department. If necessary, HPV biomarkers (especially HPV mRNA test but also HPV DNA test or p16) were ordered. The policy in all clinics was not to perform punch biopsies unless a high-grade lesion was suspected cytologically or colposcopically, but instead take into account cytology, colposcopy, HPV biomarkers (mostly mRNA, if indicated) and lifestyle risk before deciding whether treatment (usually large loop excision of the transformation zone; LLETZ) is warranted.

For each HPV-vaccinated patient, an unvaccinated control (1:1) matched for age ( \pm 3 years), education (tertiary or secondary), lifestyle (low-, middle- or high-risk) and date/place of referral (i.e. as close as possible after the referral of the case at the same Department), was selected. Women who initiated HPV vaccination after coitarche or who had started but not completed the full HPV vaccination course at coitarche or time of referral were excluded from the study.

\section{Results}

A total of 849 vaccinated women that had completed the full HPV vaccination course before onset of sexual intercourse and were referred for colposcopy due to abnormal cytology of any grade were eligible. A total of 849 matched unvaccinated controls were also selected.
Table I. Results of referral cytology.

\begin{tabular}{lcc}
\hline Cytology & $\begin{array}{c}\text { Vaccination before } \\
\text { coitarche }(\mathrm{n}=849)\end{array}$ & $\begin{array}{c}\text { Controls } \\
(\mathrm{n}=849)\end{array}$ \\
\hline HPV & $313(36.9 \%)$ & $280(33 \%)$ \\
ASC-US & $306(36 \%)$ & $209(24.6 \%)$ \\
LSIL & $228(26.9 \%)$ & $301(35.5 \%)$ \\
HSIL & $2(0.2 \%)$ & $59(6.9 \%)$ \\
\hline
\end{tabular}

ASC-US: Atypical squamous cells of undetermined significance; LSIL: low-grade squamous intraepithelial neoplasia; HSIL: high-grade squamous intraepithelial neoplasia.

The percentage of cytological high-grade squamous intraepithelial lesion (HSIL) increased from $0.2 \%(2 / 849)$ for women vaccinated before coitarche to $6.9 \%$ for unvaccinated women (Table I). Respectively, the colposcopic impression was HSIL for $0.2 \%$ (2/849) of vaccinated women and $8.7 \%$ of unvaccinated controls (Table II).

Only one woman $(0.1 \%)$ who had been vaccinated before onset of sexual intercourse required treatment (LLETZ), after taking cytology, colposcopy and HPV mRNA test into consideration. Her final histopathological diagnosis was cervical intraepithelial neoplasia grade 2 (CIN2). The other vaccinated woman with cytological and colposcopic HSIL was adolescent and there was no suspicion of CIN3+. Because CIN2 is very likely to spontaneously regress at a young age $(8,9)$, a decision for conservative management was made. On the other hand, 71 controls $(8.4 \%)$ underwent treatment, in whom the final histopathological diagnosis was CIN3 in 37 women (4\%) (Table III).

\section{Discussion}

This was an observational study comparing cervical pathology between HPV-vaccinated women at the appropriate age (i.e. before onset of sexual intercourse) and unvaccinated controls matched for several known risk factors of cervical carcinogenesis. Our results showed that cytological and colposcopic findings in women who were referred for colposcopy and had been vaccinated before coitarche, tended to be much less severe than in unvaccinated women. Respectively, only one woman $(0.1 \%)$ in the group vaccinated before coitarche needed treatment, while treatment was warranted for a significantly higher percentage in unvaccinated women $(8.4 \%,>80$-times higher). Although CIN treatments are highly effective and only $5-10 \%$ of treated women are diagnosed with residual or recurrent disease (10-13), they are associated with an increased risk of preterm birth and other adverse pregnancy outcomes in subsequent pregnancies (14-19). Less radical treatments might decrease the risk of reproductive morbidity 
Table II. Results of colposcopy.

\begin{tabular}{lcc}
\hline Colposcopy & $\begin{array}{c}\text { Vaccination before } \\
\text { coitarche }(\mathrm{n}=849)\end{array}$ & $\begin{array}{c}\text { Controls } \\
(\mathrm{n}=849)\end{array}$ \\
\hline No AWE & $180(21.2 \%)$ & $119(14 \%)$ \\
Metaplasia & $34(4 \%)$ & $21(2.5 \%)$ \\
HPV & $471(55.5 \%)$ & $491(57.8 \%)$ \\
LSIL & $162(19.1 \%)$ & $144(17 \%)$ \\
HSIL & $2(0.2 \%)$ & $74(8.7 \%)$ \\
\hline
\end{tabular}

AWE: Aceto-white epithelium; LSIL: low-grade squamous intraepithelial neoplasia; HSIL: high-grade squamous intraepithelial neoplasia.

but potentially compromise oncological outcomes; this balance between obstetrical and oncological outcomes can be better comprehended by a clinical ranking of CIN treatments through a network meta-analysis $(20,21)$. HPV vaccination at the appropriate age (i.e. before beginning of sexual life) greatly reduces the risk that a women will be diagnosed with CIN2+ and will require treatment during her lifetime.

HPV vaccines are more effective in HPV-naïve women (22). HPV vaccines are also more effective in younger compared to older individuals (regardless of sexual history), because their immunogenicity has been found to be stronger in ages under 15 years compared to older adolescents/adults $(23,24)$. Therefore, children aged 11-13 years should be the target group of HPV vaccination programmes. HPV vaccines can still be administered to sexually-active unvaccinated women, since they provide full protection against HPV types to which these women have not been exposed yet and limited protection against HPV types for which they are HPV DNA-negative, but seropositive (22). However, vaccination of sexually-active women is generally less cost-effective (25) and should be considered only on an individual basis taking into account relationship status and other lifestyle parameters. The role of HPV vaccination in unvaccinated women undergoing CIN treatment is not clear due to lack of evidence from randomised studies, but observational studies have shown that it decreases the risk of preinvasive recurrence $(26,27)$. A recent systematic review and meta-analysis showed that women previously treated for CIN are at increased longterm risk of invasive cervical and other HPV-related cancers (28), thus HPV vaccination after CIN treatment could also reduce the incidence of these HPV-related cancers in this population.

Our conclusions agree with a meta-analysis of observational studies that showed that HPV vaccination has reduced CIN2+ diagnoses in the general population by $51 \%$ in ages $15-19$ and $31 \%$ in ages 20-24 (5). A recent Scottish observational study showed that vaccinating $90 \%$ of girls
Table III. Final histopathological diagnosis in women undergoing treatment.

\begin{tabular}{lcc}
\hline $\begin{array}{l}\text { Histological examination } \\
\text { of excised cone }\end{array}$ & $\begin{array}{l}\text { Vaccination before } \\
\text { coitarche }(\mathrm{n}=849)\end{array}$ & $\begin{array}{l}\text { Controls } \\
(\mathrm{n}=849)\end{array}$ \\
\hline Treatment not needed & $848(99.9 \%)$ & $778(91.6 \%)$ \\
CIN1 & 0 & $9(1.1 \%)$ \\
CIN2 & $1(0.1 \%)$ & $25(2.9 \%)$ \\
CIN3 & 0 & $37(4.4 \%)$ \\
\hline
\end{tabular}

reduced CIN2+ diagnoses in first screening round by $88 \%$. CIN2+ diagnoses were reduced not only in vaccinated but also in unvaccinated individuals by an impressive $67 \%$ thanks to herd immunity (29). HPV vaccination has been also found to reduce cervical HPV infections (HPV 16/18 by $83 \%$ in ages $15-19,56 \%$ in ages $20-24$ and $37 \%$ in ages 25-29; HPV $31 / 33 / 45$ by $54 \%$ in ages $15-19$ ) and anogenital warts (by 67\% in ages 15-19, 54\% in ages 20-24 and 31\% in ages 25-29) (5). Because of the long natural history of HPV infection (30), it is still early to document a reduction in cervical cancer diagnoses. However, it is projected that cervical cancer will be eradicated in some countries within 20 years (3). In Greece, the Hellenic Society of HistoPathology has been running a pathology-based cancer registry since 2009 (31) with participation of almost all pathology laboratories in the public and private sector, recording the data of pre-invasive and invasive cervical disease diagnoses. Preliminary and unpublished data have shown that between the years 2009 and 2016 there has been a reduction of CIN diagnoses, probably due to HPV vaccination.

Unfortunately, HPV vaccination coverage in Greece is low and estimated at around $30-40 \%$, and HPV prevalence is still high (32). The reason for this low coverage is the fact that there is no national school-based programme and the onus of HPV vaccination lies on the parents. The main source of information for parents is paediatricians and gynaecologists, many of whom give a lukewarm (or even a negative) response when asked whether their children should be vaccinated against HPV, citing ignorance or even possible side-effects. Another source of information is the Internet where many websites deter parents from vaccination. However, more than 270 million doses have been administered in the last 10 years since HPV vaccination introduction and the evidence is clear that HPV vaccines are very safe $(33,34)$. Clinicians should be better informed so that they strongly encourage parents to vaccinate their children. Our study could also be an impetus for higher coverage rates in Greece. 
Strengths and limitations. One strength of our study is that we selected controls matched for age, education and all known lifestyle risk factors associated with a higher risk of HPV infection and cervical cancer (age at onset of sexual intercourse, number of lifetime sexual partners, smoking, frequency of condom use). In addition, this study took place soon after the introduction of HPV vaccination up to now in many academic colposcopy clinics across Greece with a high volume of referrals. One limitation of this study is that it is at risk of selection bias, since we were able to show a reduction of high-grade abnormalities after HPV vaccination only in a specific population referred for colposcopy and not in the general population. To document a reduction of CIN2+ in the general population, official nationwide registries recording CIN2+ diagnoses from public and private health sector linked with vaccination status are needed. There is a lack of such records not only in Greece but also in many other developed countries, although an initiative to collect data from all pathology laboratories has started in Greece. Finaly, it is possible that this relatively small subgroup of Greek society vaccinated before coitarche is better informed of prevention policies or health issues in general due to other potential confounders we did not adjust for. Despite these shortcomings, this Greek reality is comparable to other developed countries and the conclusions of the present study are likely applicable globaly.

\section{Conflicts of Interest}

The Authors have nothing to disclose.

\section{Authors' Contributions}

This study was designed by EP. Data from the participating hospitals were collected by EP, and were interpreted by all authors. The manuscript was drafted by EP and AA, and was revised by all authors. EP is the guarantor.

\section{References}

1 Gustafsson L, Pontén J, Bergström R and Adami HO: International incidence rates of invasive cervical cancer before cytological screening. Int J Cancer 71(2): 159-165, 1997. PMID: 9139836. DOI: 10.1002/(sici)1097-0215(19970410)71:2<159 ::aid-ijc6>3.0.co;2-\#

2 Lăăă E, Day NE and Hakama M: Trends in mortality from cervical cancer in the nordic countries: Association with organised screening programmes. Lancet (London, England) 1(8544): 1247-1249, 1987. PMID: 2884378. DOI: $10.1016 /$ s0140-6736(87)92695-x

3 Hall MT, Simms KT, Lew JB, Smith MA, Brotherton JM, Saville M, Frazer IH and Canfell K: The projected timeframe until cervical cancer elimination in australia: A modelling study. Lancet Public Health 4(1): e19-e27, 2019. PMID: 30291040. DOI: $10.1016 / \mathrm{S} 2468-2667(18) 30183-\mathrm{X}$
4 Arbyn M, Xu L, Simoens C and Martin-Hirsch PP: Prophylactic vaccination against human papillomaviruses to prevent cervical cancer and its precursors. Cochrane Database Syst Rev 5: CD009069, 2018. PMID: 29740819. DOI: 10.1002/14651858. CD009069.pub3

5 Drolet M, Benard E, Perez N and Brisson M: Population-level impact and herd effects following the introduction of human papillomavirus vaccination programmes: Updated systematic review and meta-analysis. Lancet 394(10197): 497-509, 2019. PMID: 31255301. DOI: 10.1016/s0140-6736(19)30298-3

6 Gakidou E, Nordhagen S and Obermeyer Z: Coverage of cervical cancer screening in 57 countries: Low average levels and large inequalities. PLoS Med 5(6): e132, 2008. PMID: 18563963. DOI: 10.1371/journal.pmed.0050132

7 Bruni L, Diaz M, Barrionuevo-Rosas L, Herrero R, Bray F, Bosch FX, de Sanjosé S and Castellsagué X: Global estimates of human papillomavirus vaccination coverage by region and income level: A pooled analysis. Lancet Glob Health 4(7): e453e463, 2016. PMID: 27340003. DOI: 10.1016/S2214-109X(16) 30099-7

8 Tainio K, Athanasiou A, Tikkinen KAO, Aaltonen R, Cárdenas J, Hernándes, Glazer-Livson S, Jakobsson M, Joronen K, Kiviharju M, Louvanto K, Oksjoki S, Tähtinen R, Virtanen S, Nieminen P, Kyrgiou $M$ and Kalliala I: Clinical course of untreated cervical intraepithelial neoplasia grade 2 under active surveillance: Systematic review and meta-analysis. BMJ 360 : k499, 2018. PMID: 29487049. DOI: 10.1136/bmj.k499

9 Guedes AC, Zeferino LC, Syrjänen KJ and Brenna SMF: Shortterm outcome of cervical intraepithelial neoplasia grade 2: Considerations for management strategies and reproducibility of diagnosis. Anticancer Res 30(6): 2319-2323, 2010. PMID: 20651386.

10 Arbyn M, Redman CWE, Verdoodt F, Kyrgiou M, Tzafetas M, Ghaem-Maghami S, Petry KU, Leeson S, Bergeron C, Nieminen $\mathrm{P}$, Gondry J, Reich $\mathrm{O}$ and Moss EL: Incomplete excision of cervical precancer as a predictor of treatment failure: A systematic review and meta-analysis. Lancet Oncol 18(12): 1665-1679, 2017. PMID: 29126708. DOI: 10.1016/s14702045(17)30700-3

11 Martin-Hirsch PP, Paraskevaidis E, Bryant A and Dickinson HO: Surgery for cervical intraepithelial neoplasia. Cochrane Database Syst Rev 12: Cd001318, 2013. PMID: 24302546. DOI: 10.1002/14651858.CD001318.pub3

12 Paraskevaidis E, Koliopoulos G, Malamou-Mitsi V, Zikopoulos K, Paschopoulos M, Pappa L, Agnantis NJ and Loli DE: Large loop excision of the transformation zone for treating cervical intraepithelial neoplasia: A 12-year experience. Anticancer Res 21(4b): 3097-3099, 2001. PMID: 11712817.

13 Stasinou SM, Valasoulis G, Kyrgiou M, Malamou-Mitsi V, Bilirakis E, Pappa L, Deligeoroglou E, Nasioutziki M, Founta C, Daponte A, Koliopoulos G, Loufopoulos A, Karakitsos P and Paraskevaidis E: Large loop excision of the transformation zone and cervical intraepithelial neoplasia: A 22-year experience. Anticancer Res 32(9): 4141-4145, 2012. PMID: 22993375.

14 Kyrgiou M, Koliopoulos G, Martin-Hirsch P, Arbyn M, Prendiville $\mathrm{W}$ and Paraskevaidis E: Obstetric outcomes after conservative treatment for intraepithelial or early invasive cervical lesions: Systematic review and meta-analysis. Lancet 367(9509): 489-498, 2006. PMID: 16473126. DOI: 10.1016/ s0140-6736(06)68181-6 
15 Arbyn M, Kyrgiou M, Simoens C, Raifu AO, Koliopoulos G, Martin-Hirsch P, Prendiville W and Paraskevaidis E: Perinatal mortality and other severe adverse pregnancy outcomes associated with treatment of cervical intraepithelial neoplasia: Meta-analysis BMJ 337: a1284, 2008. PMID: 18801868. DOI: 10.1136/bmj.a1284

16 Kyrgiou M, Mitra A, Arbyn M, Stasinou SM, Martin-Hirsch P, Bennett $\mathrm{P}$ and Paraskevaidis E: Fertility and early pregnancy outcomes after treatment for cervical intraepithelial neoplasia: Systematic review and meta-analysis. BMJ 349: g6192, 2014. PMID: 25352501. DOI: 10.1136/bmj.g6192

17 Kyrgiou M, Mitra A, Arbyn M, Paraskevaidi M, Athanasiou A, Martin-Hirsch PP, Bennett P and Paraskevaidis E: Fertility and early pregnancy outcomes after conservative treatment for cervical intraepithelial neoplasia. Cochrane Database Syst Rev 9: Cd008478, 2015. PMID: 26417855. DOI: 10.1002/14651858. CD008478.pub2

18 Kyrgiou M, Athanasiou A, Paraskevaidi M, Mitra A, Kalliala I, Martin-Hirsch P, Arbyn M, Bennett P and Paraskevaidis E: Adverse obstetric outcomes after local treatment for cervical preinvasive and early invasive disease according to cone depth: Systematic review and meta-analysis. BMJ 354: i3633, 2016. PMID: 27469988. DOI: 10.1136/bmj.i3633

19 Kyrgiou M, Athanasiou A, Kalliala IEJ, Paraskevaidi M, Mitra A, Martin-Hirsch PP, Arbyn M, Bennett P and Paraskevaidis E: Obstetric outcomes after conservative treatment for cervical intraepithelial lesions and early invasive disease. Cochrane Database Syst Rev 11: Cd012847, 2017. PMID: 29095502. DOI: 10.1002/14651858.Cd012847

20 Athanasiou A, Veroniki AA, Efthimiou O, Kalliala I, Naci H, Bowden S, Paraskevaidi M, Martin-Hirsch P, Bennett P, Paraskevaidis E, Salanti G and Kyrgiou M: Comparative fertility and pregnancy outcomes after local treatment for cervical intraepithelial neoplasia and stage 1a1 cervical cancer: Protocol for a systematic review and network meta-analysis from the circle group. BMJ Open 9(10): e028009, 2019. PMID: 31636110. DOI: 10.1136/bmjopen-2018-028009

21 Athanasiou A, Veroniki AA, Efthimiou O, Kalliala I, Naci H, Bowden S, Paraskevaidi M, Martin-Hirsch P, Bennett P, Paraskevaidis E, Salanti $G$ and Kyrgiou M: Comparative efficacy and complication rates after local treatment for cervical intraepithelial neoplasia and stage 1a1 cervical cancer: Protocol for a systematic review and network meta-analysis from the circle group. BMJ Open 9(8): e028008, 2019. PMID: 31377697. DOI: $10.1136 /$ bmjopen-2018-028008

22 Szarewski A, Poppe WA, Skinner SR, Wheeler CM, Paavonen J, Naud P, Salmeron J, Chow SN, Apter D, Kitchener H, Castellsague X, Teixeira JC, Hedrick J, Jaisamrarn U, Limson G, Garland S, Romanowski B, Aoki FY, Schwarz TF, Bosch FX, Harper DM, Hardt K, Zahaf T, Descamps D, Struyf F, Lehtinen $M$, Dubin $G$ and Group HPS: Efficacy of the human papillomavirus (hpv)-16/18 as04-adjuvanted vaccine in women aged 15-25 years with and without serological evidence of previous exposure to hpv-16/18. Int J Cancer 131(1): 106-116, 2012. PMID: 21858807. DOI: 10.1002/ijc.26362

23 Sow PS, Watson-Jones D, Kiviat N, Changalucha J, Mbaye KD, Brown J, Bousso K, Kavishe B, Andreasen A, Toure M, Kapiga S, Mayaud P, Hayes R, Lebacq M, Herazeh M, Thomas F and Descamps D: Safety and immunogenicity of human papillomavirus-16/18 as04-adjuvanted vaccine: A randomized trial in 10-25-year-old hiv-seronegative african girls and young women. J Infect Dis 207(11): 1753-1763, 2013. PMID: 23242542. DOI: $10.1093 /$ infdis/jis619

24 Iversen OE, Miranda MJ, Ulied A, Soerdal T, Lazarus E, Chokephaibulkit K, Block SL, Skrivanek A, Nur Azurah AG, Fong SM, Dvorak V, Kim KH, Cestero RM, Berkovitch M, Ceyhan M, Ellison MC, Ritter MA, Yuan SS, DiNubile MJ, Saah AJ and Luxembourg A: Immunogenicity of the 9-valent hpv vaccine using 2-dose regimens in girls and boys vs a 3-dose regimen in women. JAMA 316(22): 2411-2421, 2016. PMID: 27893068. DOI: 10.1001/jama.2016.17615

25 Westra TA, Rozenbaum MH, Rogoza RM, Nijman HW, Daemen T, Postma MJ and Wilschut JC: Until which age should women be vaccinated against hpv infection? Recommendation based on cost-effectiveness analyses. J Infect Dis 204(3): 377-384, 2011. PMID: 21742836. DOI: 10.1093/infdis/jir281

26 Kang WD, Choi HS and Kim SM: Is vaccination with quadrivalent hpv vaccine after loop electrosurgical excision procedure effective in preventing recurrence in patients with high-grade cervical intraepithelial neoplasia (cin2-3)? Gynecol Oncol 130(2): 264-268, 2013. PMID: 23623831. DOI: 10.1016/ j.ygyno.2013.04.050

27 Ghelardi A, Parazzini F, Martella F, Pieralli A, Bay P, Tonetti A, Svelato A, Bertacca G, Lombardi S and Joura EA: Speranza project: $\mathrm{Hpv}$ vaccination after treatment for cin2. Gynecol Oncol 151(2): 229-234, 2018. PMID: 30197061. DOI: 10.1016/j.ygyno. 2018.08 .033

28 Kalliala I, Athanasiou A, Veroniki AA, Salanti G, Efthimiou O, Raftis N, Bowden S, Paraskevaidi M, Aro K, Arbyn M, Bennett P, Nieminen P, Paraskevaidis E and Kyrgiou M: Incidence and mortality from cervical cancer and other malignancies after treatment of cervical intraepithelial neoplasia: A systematic review and meta-analysis of the literature. Ann Oncol 31(2): 213-227, 2020. DOI: 10.1016/j.annonc.2019.11.004

29 Palmer T, Wallace L, Pollock KG, Cuschieri K, Robertson C, Kavanagh $\mathrm{K}$ and Cruickshank M: Prevalence of cervical disease at age 20 after immunisation with bivalent hpv vaccine at age 12-13 in scotland: Retrospective population study. BMJ 365 : 11161, 2019. PMID: 30944092. DOI: 10.1136/bmj.11161

30 Ault KA: Epidemiology and natural history of human papillomavirus infections in the female genital tract. Infect Dis Obstet Gynecol 2006 Suppl: 40470, 2006. PMID: 16967912. DOI: $10.1155 /$ idog/2006/40470

31 Patsea E, Kaklamanis L and Batistatou A: The first report of a 5-year period cancer registry in Greece (2009-2013): a pathology-based cancer registry. Virchows Archiv 472: 677-682, 2018. PMID: 29302754. DOI: 10.1007/s00428-017-2287-8

32 Argyri E, Tsimplaki E, Papatheodorou D, Daskalopoulou D and Panotopoulou E: Recent trends in hpv infection and type distribution in greece. Anticancer Res 38(5): 3079-3084, 2018. PMID: 29715143. DOI: 10.21873/anticanres.12565

33 Phillips A, Patel C, Pillsbury A, Brotherton J and Macartney K: Safety of human papillomavirus vaccines: An updated review. Drug Saf 41(4): 329-346, 2018. PMID: 29280070. DOI: 10.1007/s40264-017-0625-z

34 GACVS: Safety update of hpv vaccines. Available at: https:// www.Who.Int/vaccine_safety/committee/topics/hpv/june_2017/en/

Received January 28, 2020

Revised February 25, 2020

Accepted March 4, 2020 